\title{
COMPARATIVE ASSESSMENT OF SODIUM EDTA AND HEPARIN AS ANTICOAGULANTS FOR THE EVALUATION OF HAEMATOLOGICAL PARAMETERS IN CULTURED AND FERAL AFRICAN CATFISH (CLARIAS GARIEPINUS)
}

\author{
ADEYEMO*1, O. K.; OKWILAGWE¹, O. O.; AJANI ${ }^{2}$, F. \\ 1. Fish and Wildlife Unit, Department of Veterinary Public Health and Preventive Medicine, \\ University of Ibadan, Ibadan, Nigeria. \\ *E-mail: olanikeadeyemo@hotmail.com / olanike.adeyemo@mail.ui.edu.ng
}

\section{Department of Animal Science and Fisheries Management, Bowen University, Iwo, Osun State, Nigeria}

\begin{abstract}
ADEYEMO, O. K.; OKWILAGWE, O. O.; AJANI, F. 2009. Comparative assessment of sodium EDTA and heparin as anticoagulants for the evaluation of haematological parameters in cultured and feral african catfish (Clarias gariepinus). Braz. J. Aquat. Sci. Technol. 13(1):19-24. ISSN 1808-7035. This study investigates the effect of anticoagulants on haematological parameters in thirty (30) feral (wild) and thirty (30) pond cultured African catfish (Clarias gariepinus). The anticoagulants used in this study were lithium heparin and sodium ethylenediaminetetraacetic acid (EDTA). Red blood cell (RBC) count, packed cell volume (PCV), hemoglobin concentration (Hb), mean corpuscular volume (MCV), mean corpuscular hemoglobin $(\mathrm{MCH})$, mean corpuscular hemoglobin concentration (MCHC), total white blood cell (WBC) count and differential count were determined. No significant differences $(p>0.05)$ were observed in the total RBC, WBC and MCHC values in the feral and pond cultured fish. In the pond cultured African catfish, the neutrophil values were significantly higher $(p=0.001)$ than those of the feral African catfish irrespective of the anticoagulant used. The values for PCV, Hb, lymphocytes, eosinophils, MCV and MCHC of the feral African catfish were significantly higher $(p<0.05)$ than those of the pond cultured African catfish irrespective of the anticoagulant used. The monocyte value for the feral fish was significantly higher $(p=0.041)$ when EDTA was used as the anticoagulant. This study therefore concludes that both anticoagulants could be used for haematological evaluation of fish blood. Also, the habitat and environmental conditions should be taken into consideration when analyzing blood samples in fish.
\end{abstract}

Keywords: Haematology, EDTA, Heparin, African catfish

\section{INTRODUCTION}

Blood tissue reflects physical and chemical changes occurring in an organism, therefore detailed information can be obtained on general metabolism and physiological status of fish in different groups of age and habitat (Kocabatmaz \& Ekingen, 1978). One of the difficulties in assessing the state of health of natural fish population has been the paucity of reliable references of the normal condition. In pursuant to this goal, many fish physiologists have turned to studies of haematology. Many of the clinical tools used to evaluate mammalian health are not developed for use in fishes. As the aquaculture industry expands, there is an increasing need for improved diagnostic methods. There are few tools available to diagnose and monitor disease in African catfish, tilapia and other species of fish. One such tool is the analysis of blood; it can help detect acute and chronic pathophysiological changes attributable to nutrition, water quality, toxicants, and disease.
Interpretation of fish haematological data is quite difficult due to internal and external variation. It is well known that blood sampling, laboratory techniques, seasonal variations, size and ontogeny of habitat, genetic properties, sex, population density, geographical dispersion, lack of food supply and stress, $\mathrm{pH}$, water and transportation affect haematological data (Hardig \& Höglung, 1984; Wilhem Filho et al., 1992; Rehulka \& Adamec, 2004). However, only a few normal values for a small number of hematological parameters have been established for some teleosts, but these values range widely due to the lack of standardized collecting and measuring techniques (Blaxhall, 1972). To determine haematological values, it is of importance that the blood collected be kept in sample bottles containing anticoagulants. This project therefore seeks to analyze and compare blood parameters in relation to the use of two major anticoagulants in African catfish (Clarias gariepinus). For the purpose of this project, heparin and sodium ethylenediaminetetracetic acid (EDTA) are the 


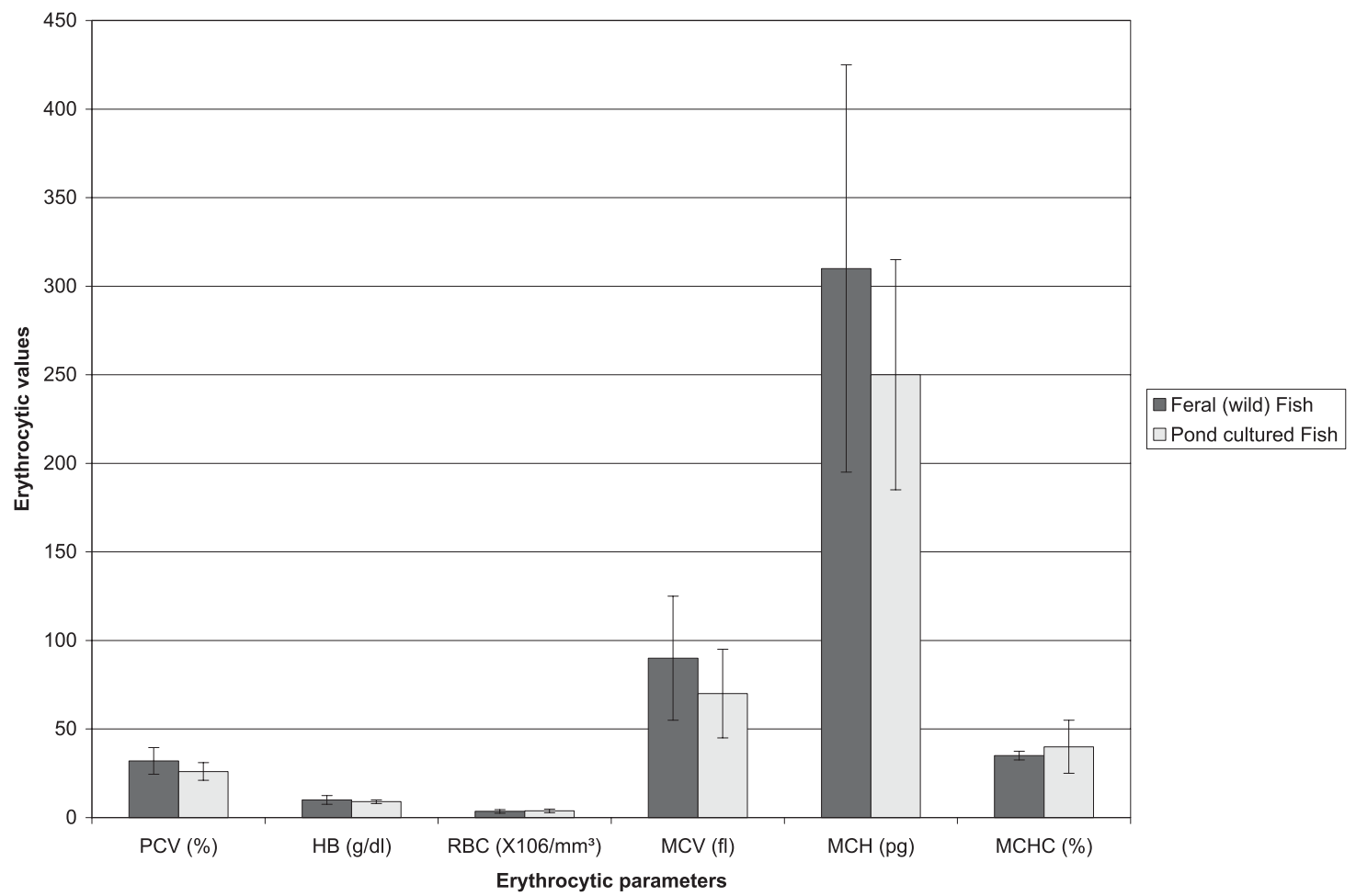

Figure 1 - Comparison between the Erythrocytic parameters of feral and pond cultured African catfish.

anticoagulant used for the evaluation of haematological parameters in cultured and feral African mud catfish and this is mainly because these anticoagulants are the most readily available for use in laboratories in Nigeria. It is expected that the results from this study will be useful in establishing a haematological data bank for these fish species including the ideal anticoagulant for haematological studies in African catfish.

\section{MATERIALS AND METHODS}

\section{The Experimental Fishes}

A total of Sixty (60) apparently healthy adult African catfish, Clarias gariepinus, (mean weight $543 \mathrm{~g}$ $\pm 100 \mathrm{~g}$ and mean length $27 \mathrm{~cm} \pm 3 \mathrm{~cm}$ ) were purchased at the early hours (6:00-7:00 am) of the morning to reduce stress on the fish and blood samples were collected about thirty minutes after purchase. The fishes used for this study were purchased at ten from three private fish ponds $(\mathrm{N}=30)$ and thirty $(\mathrm{N}=30)$ from fresh water body (Eleyele River) within the lbadan metropolis.

\section{Collection of Blood Samples}

Two milliliters of blood was collected through the caudal vein located just beneath the backbone of the fish, by ventral venous puncture with the use of a sterile syringe and decanted into heparinized bottles $(4 \mathrm{mg} /$ $\mathrm{mL}$ of blood) and sodium EDTA bottles $(0.5 \mathrm{mg} / \mathrm{mL}$ of blood)) respectively. Blood samples were then rocked gently to allow mixture with the anticoagulants, to prevent clotting and hemolysis. The blood samples were analyzed within 3 hours of collection to ensure accurate laboratory results.

\section{Determination of Haematological Parameters}

To determine the count of erythrocytes blood sample was diluted (1/200) with the Hayem's solution. One drop of blood was transferred onto Thoma lamella and determined under a light microscope (Soif, XZS107B model) with a magnification of 400x (Blaxhall, 1972). Leukocyte count was performed by aspirating blood sample (diluted in Turk's solution) with a leukocytes pipette onto counting lamella and determined under a light microscope (Blaxhall, 1972). The hemoglobin was determined according to the cyanomethemoglobin method (Hesser, 1960). Unclotted blood $(20 \mu \mathrm{L})$ was diluted with Drabkin's solution $(1 \mathrm{~mL})$ and left to stand for $10 \mathrm{~min}$. The absorbency of the mixture was read at $540 \mathrm{~nm}$. The microhematocrit method was used to determine the hematocrit. Unclotted blood was aspirated into microhematocrit pipette and centrifuged at $12.5 \mathrm{rpm}$ for $5 \mathrm{~min}$. RBC was estimated using the relationship between $\mathrm{Hb}$ and PCV (Mirale, 1982). Giemsa stained sample examined under a binocular light microscope (Soif, XZS-107B model) at $100 x$ magnification was used to determine the leukocyte count and differential WBC counts (Stoskopf, 1993). 


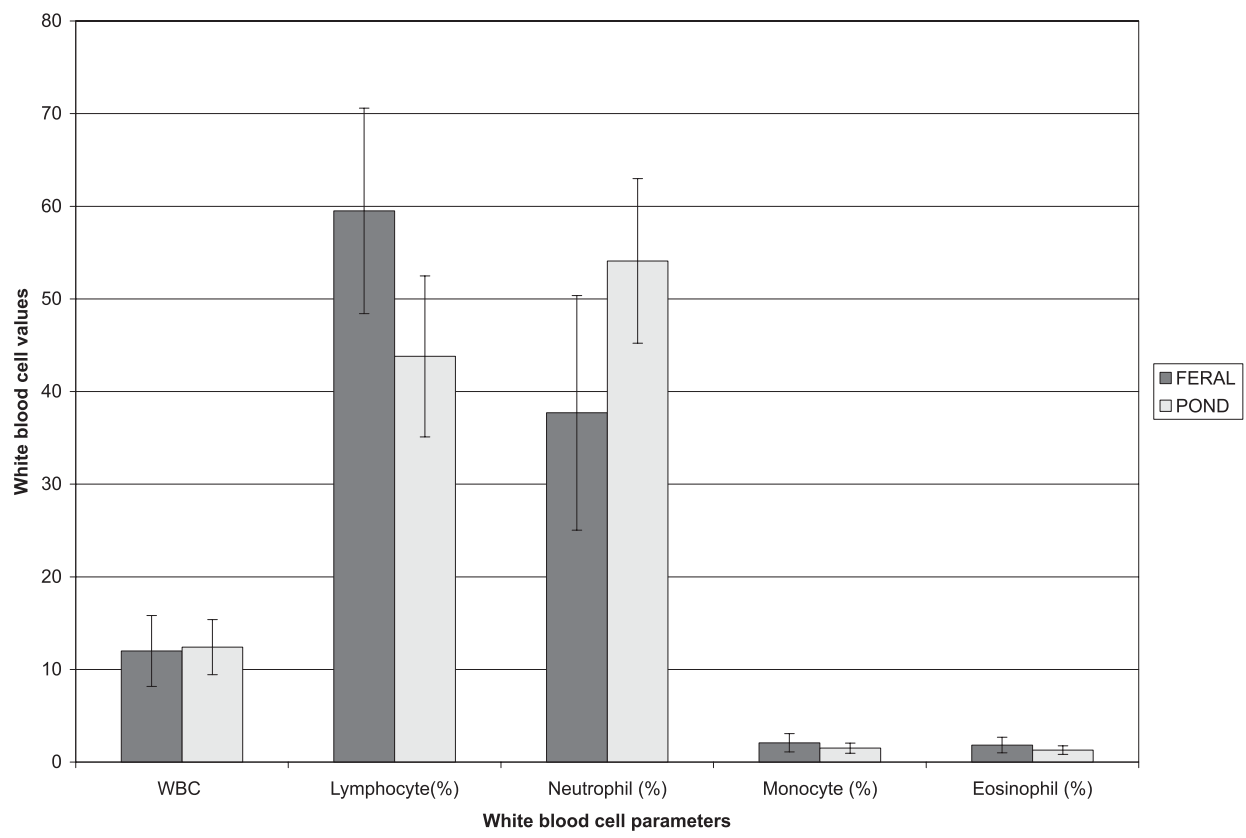

Figure 2 - Comparison between the White blood cell parameters of feral and pond cultured African catfish.

\section{Statistical Analysis}

The data are presented in figures as mean \pm standard deviation (SD). The differences in the hematological parameters were determined using student's t-test. The differences were assessed using two anticoagulants (EDTA and heparin) and two environments (feral and culture) as indices. The confidence limit was $95 \%$ for all the tests conducted.

\section{RESULTS AND DISCUSSION}

Aquaculture urges for more accurate information on stress control, in order to ensure health of fish under culture environment. Hematological parameters can be of great importance to fish farmers, serving as indicators of the physiological status and helping to prevent and control pathologies related to stress (Aldrin et al, 1982).

In this study; RBC, MCHC, WBC values (Figures 1 and 2 ) were not significantly different $(p=0.80,0.75$, 0.48 , respectively) in both feral and pond cultured African catfishes. However, the feral catfish, demonstrated significantly higher PCV, $\mathrm{Hb}, \mathrm{MCV}, \mathrm{MCH}$, lymphocytes, monocytes and eosinophils values $(p=0.001$ for all except monocytes with $p=0.01$ ). Higher hematological parameters might have resulted from the difference in water temperature and oxygen concentration of the culture environment (Kocabatmaz \& Ekingen, 1978); while an increase in leucocytes has been attributed to stress conditions; which is more common under feral condition relative to the more conducive pond environment (Schreck et al. 1976). High MCV suggests that a hemo-dilution mechanism is operational; the mean corpuscular volume gives an indication of the status or size of the red blood cells and reflects an abnormal/ normal cell division during erythropoiesis. The increase in MCV may be attributed to the swelling of the erythrocytes resulting in macrocytic anemia. Such an increase in erythrocyte size is generally considered a response against stress and would be a consequence of several factors like high PCO2, high lactate concentration or low PO2 in the blood, leading to a low ATP concentration, which would increase the oxygen affinity of blood (Soivo \& Nikinmaa, 1981). In this instance, it is difficult to ascribe the swollen red blood cells to one of these factors; the increase in MCV observed, therefore, needs further elucidation.

Figures 3 and 4 show that there were no significant differences $(p=0.88,0.85,0.14,0.28,0.75$, $0.20,0.86,0.78,0.73$ ) between the PCV, Hb, RBC, MCV, $\mathrm{MCHC}, \mathrm{MCH}, \mathrm{WBC}$, monocytes and eosinophils values, respectively when Heparin and EDTA were used as anticoagulants for evaluating the haematological parameters in pond-cultured African catfish. This suggests that both heparin and EDTA are suitable for haematological analysis in catfish; with a certainty of comparable results. However, there were significant differences $(p=0.01,0.05)$ in the lymphocyte and neutrophil values respectively (Figure 4). This variation in lymphocyte and neutrophil values may be due to sex dependent differences, which was not fathomed into this study. However, studies have shown that total leukocyte, neutrophil, and monocyte ratios, were higher in females at reproduction periods than in males (Murray, 1984; Orun \& Erdeml, 2002).

The choice of anticoagulant had no significant effect on haematological parameters of feral African catfish (Figure 5), but MCH was significantly higher 


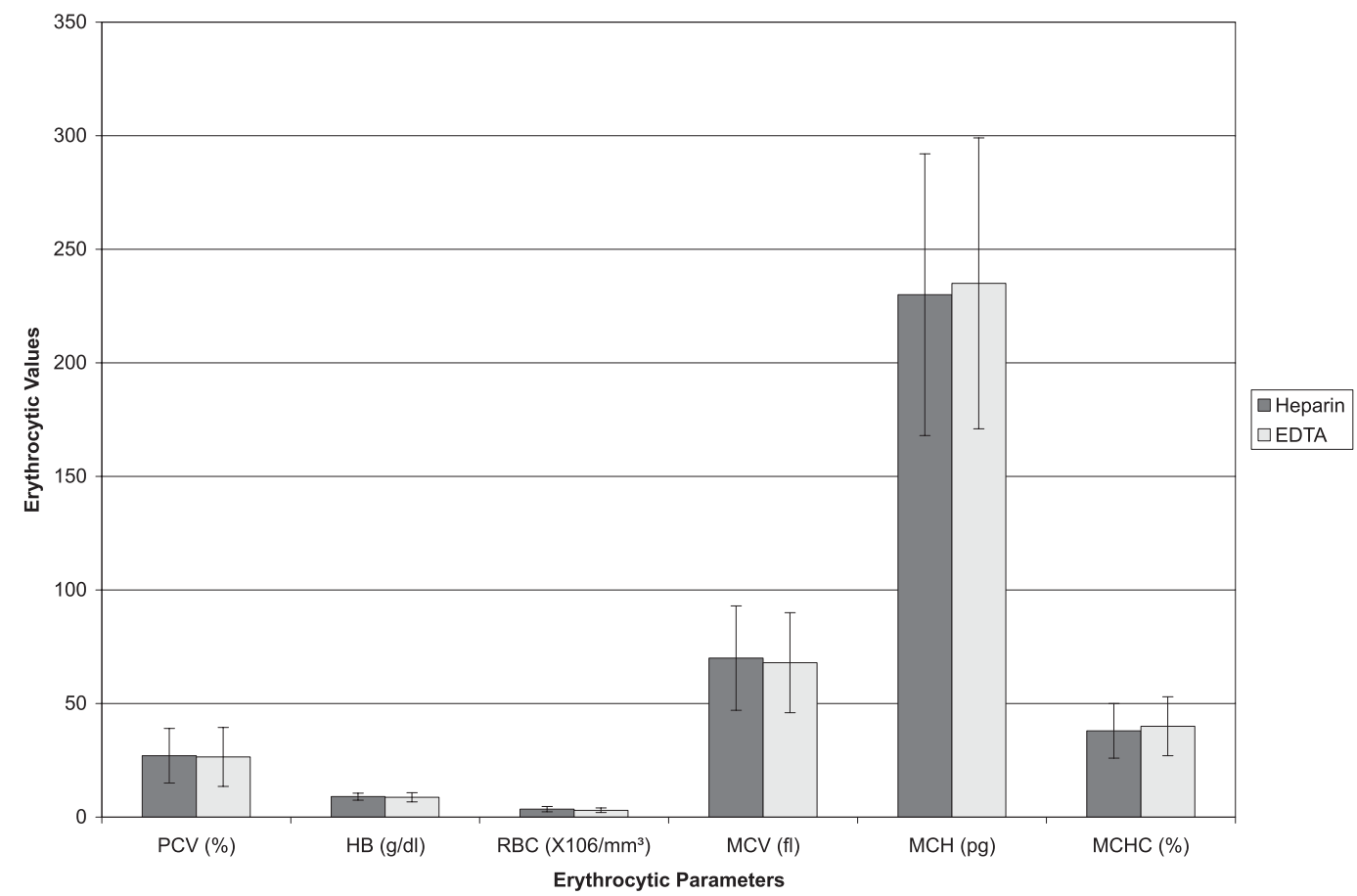

Figure 3 - Comparison between the effect of Heparin and EDTA as anticoagulants on the Erythrocytic parameters in pond cultured African catfish.

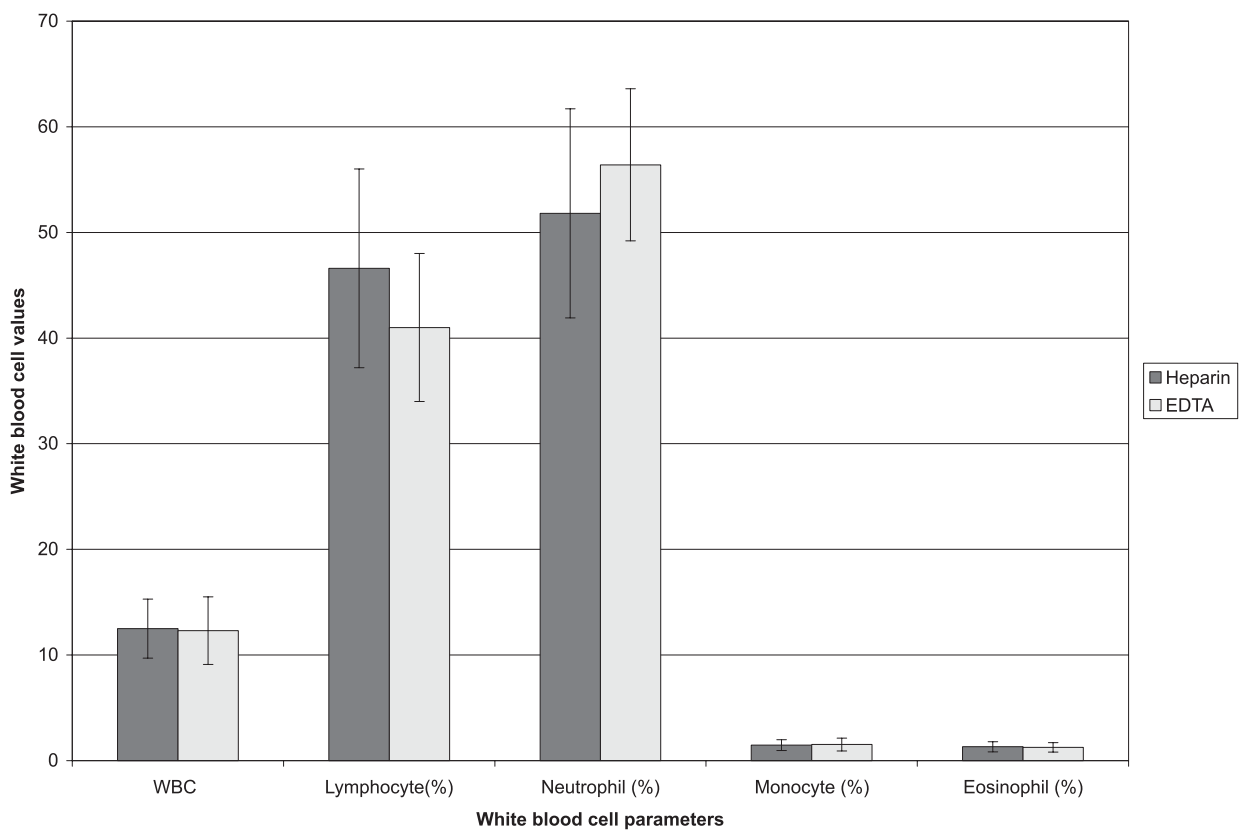

Figure 4 - Comparison between the effect of Heparin and EDTA as anticoagulants on the White blood cell parameters in pond cultured African catfish.

$(p=0.035)$ when heparin was used, whereas monocyte count was significantly higher $(p=0.041)$ with the usage of EDTA (Figures 6 ). This study also noted that the pond cultivated African catfish recorded high mean values in their neutrophils (Figures 2, 4, 6) irrespective of the anticoagulants used. PCV, $\mathrm{Hb}, \mathrm{MCV}, \mathrm{MCH}$ and lymphocyte values were also generally higher in feral African catfish irrespective of the anticoagulant used.
In conclusion, the variation in methodology used for hematological studies, instant changes in physical and chemical properties of micro-environment in which fish lives makes comparison of literature and the establishment of limits for hematological data difficult. Therefore, we propose separate data collection and comparison from healthy and unhealthy fish and also between sexes to obtain further hematological data. 


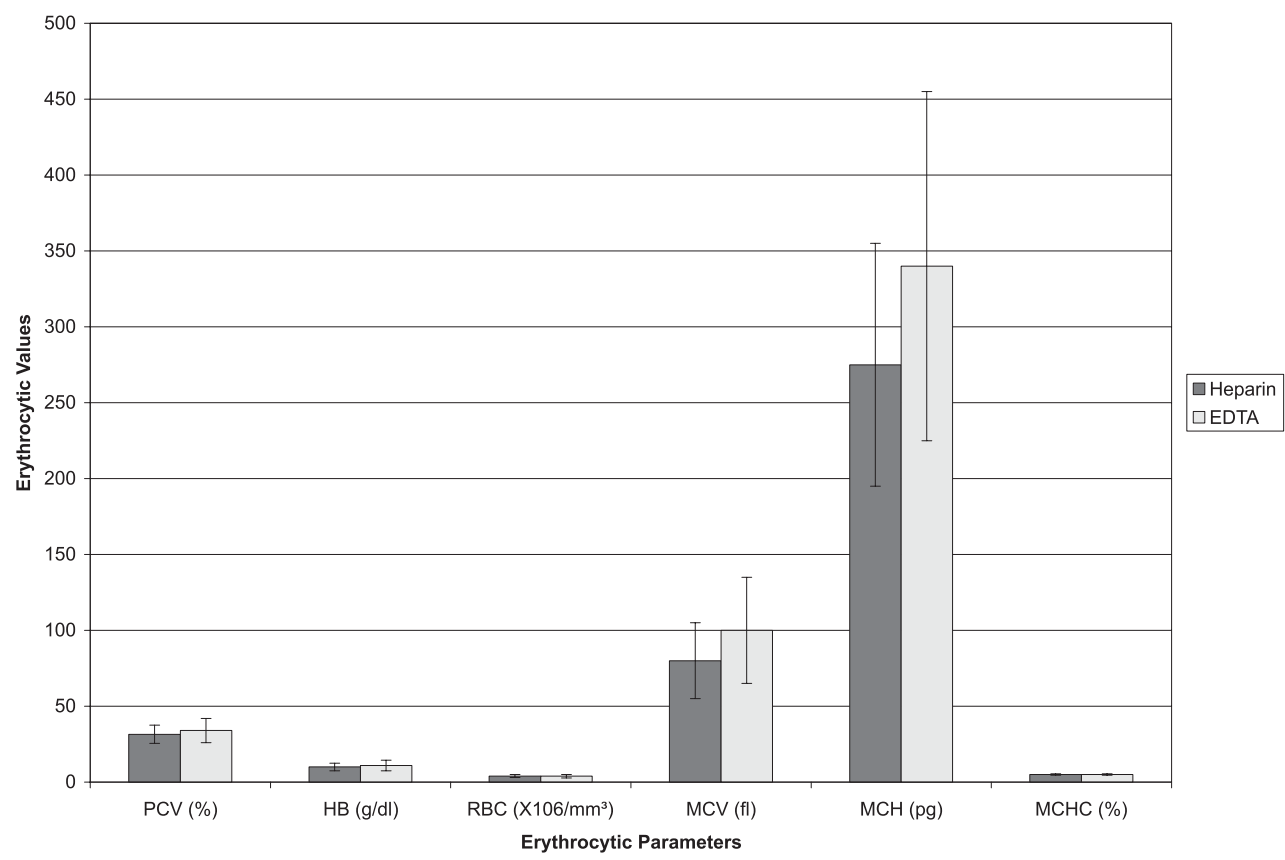

Figure 5: Comparison between the effect of Heparin and EDTA as anticoagulants on the Erythrocytic parameters in feral African catfish.

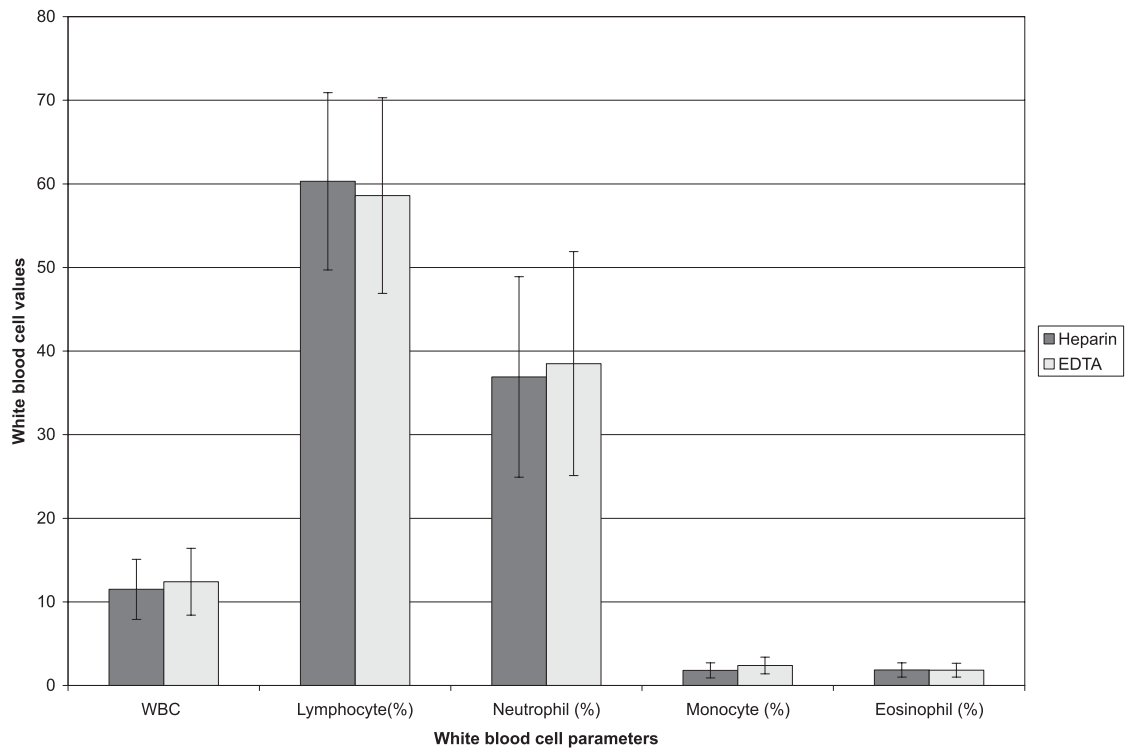

Figure 6 - Comparison between the effect of Heparin and EDTA as anticoagulants on the White blood cell parameters in feral African catfish.

\section{REFERENCES}

Aldrin, J.F.; Messager, J.L. \& Baudin-Laurencin, F. 1982. La biochimie clinique en aquaculture. Interet et perspective. Cnexo Actes Colloq. 14:219-326.

Blaxhall, P.C. 1972. The haematological assessment of health of freshwater fish. A review of selected literature. J. Fish Biol. 4: 593 - 604.

Hardig, J. \& Höglung, L.B. 1984. Seasonal variation in blood sedimentation rate and components of reared Baltic Salmon, Salmon salar L. J. Fish Biol. 24: 565-579.
Hesser, E.F. 1960. Methods for routine fish hematology. Progressive Fish Culturist, 22(4): 164-171.

Kocabatmaz, M.E. \& Ekingen, G. 1978. Bes tatlisu baligi türünde bazi hematolojik normlar üzerine ön çalismalar. Firat Üniversitesi Veterinerlik Fakültesi Dergisi. 4:223-232

Mirale, J.B. 1982. Laboratory medicine haematology. 6th edition. The CV Mosby Pub. London, p. 883

Murray, S.A. 1984. Hematological study of the bluegill Lepomis macrochirus. Raf. Comparative Bioch. Physiol. 78A: 787-791 
Örün A. \& Erdeml A.Ü. 2002. A Study on Blood Parameters of Capoeta trutta (Heckel, 1843. Online Journal of Biological Sciences. 2 (8): 508-511.

Rehulka, J. \& Adamec, V. 2004. Red blood cell indices for rainbow trout (Oncorhynchus mykiss walbaum) reared in cage and raceway culture. Acta vet. Brno. 73: $105-114$

Rimsh, E.Y. \& Adamova, L.G. 1973. Blood analysis of herbivores fish (Efficiency of natural reproduction and rearing of valuable commercial fishes). Fish Res. Biol. Canada. Series No: 2620.

Schreck, C. B., Whaley, R.A.; Bass, M.L.; Maughan, O.E. \& Solazzi. M. 1976. Physiological responses of rainbow trout (Salmo gairdneri) to electroshock. J. Fish. Res. Board Can. 33:76-84

Soivo, A. \& Nikinmaa, M. 1981. The swelling of erythrocytes in relation to the oxygen affinity of the blood of the rainbow trout, Salmo gaidneri (Richardson). In Pickering, A.D. (ed.) Stress and Fish. Academic Press, London. 103-119 pp.

Stoskopf, M.K. 1993. Clinical pathology. In M.K. Stoskopf (Ed.) Fish Medicine (pp. 113-131). Philadelphia, Pa: WB Saunders.

Wilhelm Filho, D.M.; Eble, G.J.; Kassner, G.; Caprario, F.X.; Dafre, L.A. \& Ohira, M. 1992. Comparative hematology in Marine fish. Comparative Biochem. Physiol. 102A: 311-321. 